STOMACH

\title{
Human peripheral and gastric lymphocyte responses to Helicobacter pylori NapA and AphC differ in infected and uninfected individuals
}

\author{
H J Windle, Y S Ang, V A Morales, R McManus, D Kelleher
}

Gut 2005;54:25-32. doi: 10.1136/gut.2003.025494

See end of article for authors' affiliations

Correspondence to:

Dr H Windle, Trinity

Centre for Health Sciences,

Department of Clinical

Medicine, St James's

Hospital,' Dublin 8, Ireland;

hiwindle@tcd.ie

Revised version received 31 March 2004

Accepted for publication

10 May 2004

Background: In this study, we identify the nature of the immunological response of human peripheral blood mononuclear cells (PBMC) and lamina propria gastric lymphocytes (LPL) to two Helicobacter pylori antigens, the neutrophil activating protein (NapA) and alkyl hydroperoxide reductase (AphC). These antigens were identified and selected for study based on the observation that serological recognition of these proteins was associated with $H$ pylori negative status in humans.

Aims: The aim was to study the serological, proliferative, and cytokine responses of PBMC and LPL, obtained from $\mathrm{H}$ pylori infected and uninfected individuals, to these antigens.

Methods: Patient serum, PBMC, and LPL were used to determine antibody isotype, and proliferative and cytokine responses to recombinant forms of NapA and AphC using western blotting and ELISA.

Results: Western blotting revealed antibody reactivity to recombinant NapA and AphC among the $H$ pylori negative population studied. Both the proliferative and interferon $\gamma$ responses of PBMC and LPL to NapA and AphC were significantly higher in $\mathrm{H}$ pylori negative compared with $\mathrm{H}$ pylori positive subjects. Analysis of the $\lg G$ subclass profiles to both antigens revealed a $T$ helper 1 associated $\lg G 3$ antibody response in uninfected individuals. However, interleukin 10 production was greater in $\mathrm{H}$ pylori positive individuals in response to these antigens.

Conclusions: Taken together these data are consistent with an immune response to these antigens skewed towards a T helper 1 response in the uninfected cohort.

$\mathrm{H}$ elicobacter pylori specifically colonises human gastric epithelium, is a major cause of chronic gastritis, and is strongly associated with peptic ulcer disease and the development of gastric cancer. ${ }^{1-3}$ Colonisation of the gastric epithelium by the bacterium results in an inflammatory reaction consisting of elements of both the humoral and cellular immune response. However, the immune response mounted by the host is ineffective in eliminating $H$ pylori from the stomach lumen. ${ }^{4}$ Eradication of the organism is believed to be a rare event once colonisation is established. In addition to strain dependent gene expression by $H$ pylori, host factors are also thought to influence disease outcome. The vast majority of individuals colonised by $H$ pylori elicit a measurable systemic antibody response that may reflect the specificity of those antibodies produced at the gastric mucosa. ${ }^{5}$ The Ig classes and subclasses of these circulating anti- $H$ pylori antibodies are consistent with a prolonged chronic mucosal infection, with IgG and IgA predominating and IgM antibodies rarely observed..$^{6-9}$ Despite the production of such antibodies, the infection persists and gastritis progresses chronically. However, following eradication of $H$ pylori, specific antibody levels decline slowly ${ }^{10}$ but can be detected by immunoblot for at least two years post eradication. ${ }^{11}$ Reinfection is accompanied by a rapid rise in antibody titre. ${ }^{12}$ These observations support the view that anti- $H$ pylori antibodies are not protective and only reflect the chronicity of infection. Of note, reports in the literature indicate that spontaneous eradication of $H$ pylori can occur, particularly in the paediatric population ${ }^{813-19}$ Of the two documented ingestion studies ${ }^{20}$ one reported elimination of an acute infection whereas the other proceeded to develop chronic colonisation. Little attention has been paid however to the systemic and humoral immune responses of $H$ pylori uninfected seropositive individuals to $H$ pylori antigens.
In this paper, we demonstrate that $H$ pylori negative individuals have detectable antibody responses to several $H$ pylori antigens, including the neutrophil activating protein (NapA; HP0243, The Institute for Genomic Research annotation, www.tigr.org) and alkyl hydroperoxide reductase (AphC, HP1563). We present the proliferative and cytokine (interleukin 10 (IL-10), interferon $\gamma($ IFN- $\gamma)$ ) responses of human peripheral blood mononuclear cells (PBMC) and lamina propria lymphocytes (LPL) to NapA and AphC in $H$ pylori positive and negative individuals. The different immune responses to these antigens by both cohorts may have implications for disease progression.

\section{MATERIALS AND METHODS}

Materials

All antibodies were obtained from Sigma Chemical Co. (Poole, Dorset, UK), Dako Ltd (High Wycombe, UK), or the Binding Site Ltd (Birmingham, UK). All other chemicals and solvents, except where indicated, were obtained from Sigma. Reagents for DNA manipulation were obtained from either Promega Corporation (Madison, Wisconsin, USA) or New England Biolabs (Beverly, Massachusetts, USA). Recombinant urease B subunit (UreB) was obtained from Austral Biologicals (California, USA).

\footnotetext{
Abbreviations: IFN- $\gamma$, interferon $\gamma$; IL-10, interleukin 10; LPL, lamina propria lymphocytes; NapA, neutrophil activating protein; PBMC, peripheral blood mononuclear cells; rUreB, recombinant urease $B$ subunit; AphC, alkyl hydroperoxide reductase; PBS, phosphate buffered saline; SDS-PAGE, sodium dodecyl sulphate-polyacrylamide gel electrophoresis; PCR, polymerase chain reaction; HPS, H pylori sonicate
} 


\section{Sera samples}

Serum samples were obtained from individuals undergoing gastrointestinal endoscopy at St James's Hospital, Dublin. Infection in these patients was determined and confirmed by histological examination of endoscopic biopsy specimens, CLO testing, and culture of the bacterium in vitro. The studies described herein were approved by the ethics committee of the Federated Dublin Voluntary Hospitals. Serum samples were also collected from the cohort of patients described below for PBMC and LPL and additional immunoblotting studies.

\section{Subjects used for PBMC/LPL studies}

Sixty patients with dyspepsia ( 30 females, 30 males; age range 18-67 years (median 40)) were studied. All of these patients were attending for upper gastrointestinal endoscopy. All patients had antral biopsies performed to obtain gastric LPL. None of the patients had received non-steroidal antiinflammatory drugs, bismuth compounds, or antibiotics in the preceding 12 months. Patients with evidence of malignant disease or immunosuppression were excluded. $H$ pylori was identifiable in tissue sections by haematoxylin-eosin staining. Seropositivity for H pylori was determined by ELISA.

\section{Absorption of sera}

Sera (diluted 1/50 with phosphate buffered saline (PBS)) were absorbed with a pooled mixture of two clinical isolates of $H$ pylori in addition to the reference strain NCTC 11638, Esherichia coli (K12), or Campylobacter jejuni (clinical isolate) by incubating a suspension of the bacteria $\left(10^{9}\right.$ bacteria $/ \mathrm{ml}$; McFarland standards) in PBS ( $\mathrm{pH} 7.5$ ) with patient sera for two hours at room temperature with gentle mixing. The bacteria were removed from suspension by centrifugation (12000 g, three minutes). Additionally, for some experiments (figs 2,4), sera were adsorbed with a whole cell sonicate of $H$ pylori (pooled strains N6 and NCTC 26695) or sonicates of $C$ jejuni, Enterobacter aerogenes, Salmonella

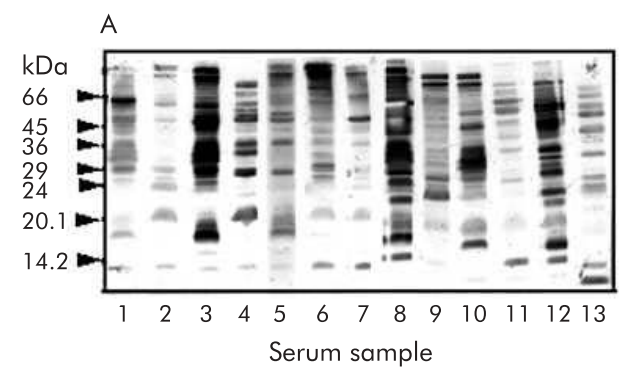

B

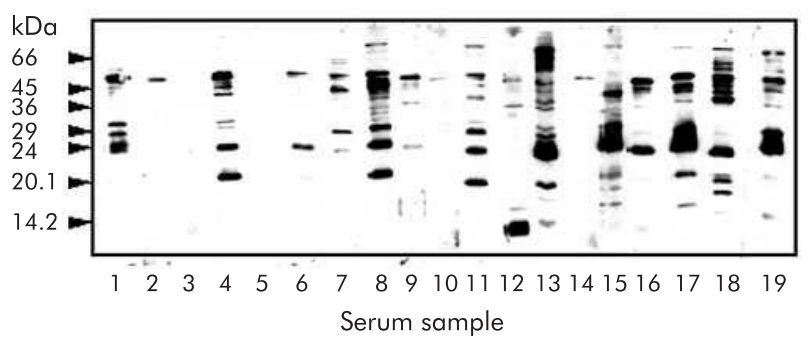

Figure 1 Serum samples screened for the presence of anti-Helicobacter pylori lgG antibodies. Western blots of whole $\mathrm{H}$ pylori ( $50 \mu \mathrm{g} / \mathrm{lane})$ probed with serum obtained from $\mathrm{H}$ pylori infected (A) and $\mathrm{H}$ pylori uninfected (B) cohorts are shown. All sera were diluted 1:100 in phosphate buffered saline containing fat free dried skimmed milk $15 \%$ $\mathrm{w} / \mathrm{v}$ ). Each track represents an individual strip of PVDF membrane which had been incubated with a different serum sample. Blots were developed by enhanced chemiluminescence. typhimurium, or Yersinia pseudotuberculosis. In this case, bacteria were harvested in PBS and subjected to sonication ( $3 \times 30$ second bursts, amplitude setting $10 \mu \mathrm{m}$ on a MSE Soniprep 150). The sonicates were diluted to an OD of 0.8 $(600 \mathrm{~nm})$ and used for adsorption studies. Sera were diluted $1 / 50$ in the sonicate and incubated overnight $\left(4^{\circ} \mathrm{C}\right)$ with rotary mixing. Prior to use for immunoblotting, the various adsorbed sera were diluted with blocking buffer (PBS, 10\% $(\mathrm{w} / \mathrm{v})$ non-fat milk powder and Tween-20 $(0.01 \%, \mathrm{v} / \mathrm{v}))$ to give a final $1 / 100$ dilution of each serum sample.

\section{Bacterial strains and growth conditions}

The clinical isolates of $H$ pylori used in this study were isolated from antral biopsies obtained from patients attending the Gastroenterology Clinic at St James's Hospital, Dublin. $H$ pylori was grown as described previously. ${ }^{22} \mathrm{~A}$ clinical isolate of $C$ jejuni from a patient with $C$ jejuni enteritis and a reference strain (HS:19) were grown for two days on campylobacter selective supplement (Oxoid, Basingstoke, UK) at $42^{\circ} \mathrm{C}$. E coli $\mathrm{K} 12$ was purchased from Gibco (Grand Island, USA) and was grown under standard conditions on LB agar plates. E aerogenes (NCTC 9528), S typhimurium (ATCC 19585), and $Y$ pseudotuberculosis (IP 2627) were grown on LB agar.

\section{Western blotting and SDS-PAGE}

Sodium dodecyl sulphate-polyacrylamide gel electrophoresis (SDS-PAGE) and western blotting were performed essentially as described previously. ${ }^{22}{ }^{23}$ Immunoblots were processed and developed by enhanced chemiluminescence. For $\mathrm{N}$ terminal sequencing, proteins were electroblotted to ProBlott.

\section{Purification of NapA and AphC}

Both the NapA and AphC antigens were purified from whole $H$ pylori (strain 11638; $25 \mathrm{mg}$ ) on the basis of molecular weight using preparative continuous elution SDS-PAGE on a Model 491 Prep-Cell (BioRad, Hemel Hempstead, UK), as recommended by the manufacturer.

\section{Cloning of the $\boldsymbol{H}$ pylori nap $\boldsymbol{A}$ gene}

Genomic DNA was extracted from H pylori (NCTC 11638) as described previously. ${ }^{24}$ Oligonucleotide primers specific for the $5^{\prime}$ and $3^{\prime}$ termini of the napA gene were generated. The forward primer (F) was designed to incorporate an Ndel restriction endonuclease site while the reverse primer $(\mathrm{R})$ incorporates a BamHl restriction site. The primer sequences were: F, 5'-GAA GGA CTT CAT ATG AAG ACA TTT G -3' and $\mathrm{R}, 5^{\prime}$-CGT GAA TGG ATC CTC ATG CTG ACT TCT-3'. The napA gene sequence was amplified in a "hotstart" polymerase chain reaction (PCR) using 50-100 ng of $H$ pylori DNA. A "touchdown" PCR procedure ${ }^{25}$ was utilised. The reaction products were purified on a $4 \%$ low melting point agarose gel and recovered following $\beta$-agarase 1 digestion. Approximately $3 \mu \mathrm{g}$ of purified DNA fragment corresponding to the napA gene was then digested with the restriction enzymes Ndel and BamHl, each of which occurs only once on the amplified fragment.

\section{Cloning of aphC}

The following primers were used to amplify the entire sequence of aphC for cloning in an expression vector (pETl6b: Novagen, Madison, USA). Forward primer: 5' GAC TGA TAG CAT ATG TTA GTT ACA AAA CTT GC-3'; reverse primer: 5' -AGC TTA ATG GAT CCT TCT TAA AGA TAT TCT GCA ACG-3'. The forward primer was modified to include an Ndel site and the reverse had a built in BamHI site. The insert was amplified, digested with the appropriate enzymes, and ligated into the expression vector pET16b. 


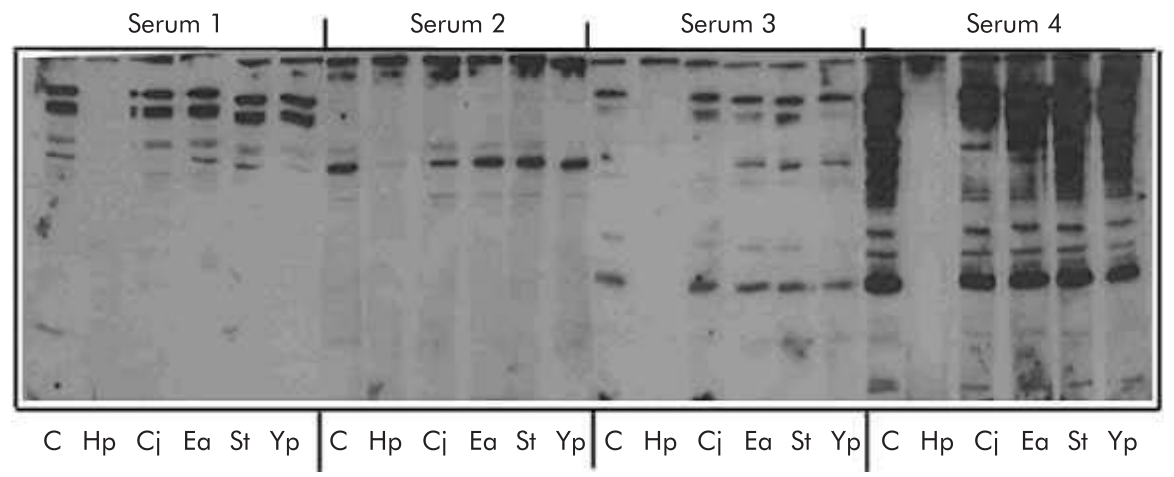

Figure 2 Adsorption of sera from infected and uninfected seropositive subjects. Serum $(40 \mu)$ ) from either uninfected (sera 1, 2, 3) or infected (serum 4 ) individuals was either untreated (C) or adsorbed with sonicates of $H$ pylori $(\mathrm{Hp}), \mathrm{C}$ jejuni $(\mathrm{Ci}), E$ aerogenes $(\mathrm{Ea}), S$ typhimurium $(\mathrm{St})$, or $Y$ pseudotuberculosis (Yp) prior to probing blots of whole Helicobacter pylori (NCTC26695) with each serum sample. Primary lgG was detected with horseradish peroxidase conjugated rabbit antihuman $\lg G(1 / 3000)$ and developed by enhanced chemiluminescence.

\section{Expression and purification of the recombinant products}

The expression vector used was pET16b (Novagen); $1.6 \mu \mathrm{g}$ of the vector were digested using $\mathrm{Ndel}$ and BamHl. Approximately $200 \mathrm{ng}$ of pET16b were ligated to approximately $100 \mathrm{ng}$ of the appropriate insert DNA with 3 units of T4 DNA ligase at $20^{\circ} \mathrm{C}$ for 16 hours. The products of this reaction were used to transform competent $E$ coli XL1-blue cells. Plasmids with appropriate inserts were used to transform $E$ coli expression hosts (BL21 DE3 and NOVAblue DE3). Overexpression was induced by the addition of IPTG ( $1 \mathrm{mM})$. The antigens were purified as recommended by the manufacturer on Ni-NTA agarose.

\section{$\lg$ G ELISA}

\section{Polyclonal IgG ELISA}

All steps were performed at room temperature. ELISA plates (Nunc Maxisorp, Roskilde, Denmark) were coated with recombinant NapA or AphC $(1 \mu \mathrm{g} / \mathrm{ml} ; 50 \mu \mathrm{l} /$ well $)$ in PBS $(\mathrm{pH} 7.4)$ for three hours. After washing with PBS and blocking with bovine serum albumin ( $3 \% \mathrm{w} / \mathrm{v} ; 150 \mu \mathrm{l} /$ well) in PBS for one hour the plates were washed with PBS and serum ( $50 \mu \mathrm{l}$; diluted $1 / 50$ in PBS) was added to duplicate wells and incubated for one hour. Controls consisted of wells with PBS alone and $H$ pylori sonicate $(1 \mu \mathrm{g} / \mathrm{ml})$ as negative and positive controls, respectively. Peroxidase conjugated antihuman IgG (1/5000) was added and incubated for one hour after which time the plates were washed with PBS and the colour reaction was initiated by addition of TMB $(50 \mu \mathrm{l})$. After 10 minutes the reaction was terminated by addition of $\mathrm{l} \mathrm{M}-\mathrm{H}_{2} \mathrm{SO}_{4}(50 \mu \mathrm{l})$ and the colour intensity was measured at $450 \mathrm{~nm}$.

\section{$\lg G$ subclass ELISA}

Detection of specific IgG subclasses was achieved by adding $50 \mu \mathrm{l}$ of alkaline phosphatase conjugated anti-IgG subclasses (IgG 1-4) at a dilution of $1 / 5000$ in PBS. The colour reaction was initiated by addition of $50 \mu \mathrm{l}$ p-nitrophenyl-phosphate $(1 \mathrm{mg} / \mathrm{ml}$ in $10 \%$ diethanolamine buffer, $\mathrm{pH} 9.8)$ and incubated in the dark for 10 minutes. The reaction was terminated by addition of $50 \mu \mathrm{l} \mathrm{NaOH}(3 \mathrm{M})$. The plates were read at $405 \mathrm{~nm}$.

\section{PBMC and LPL proliferation studies}

Venesections were performed for isolation of PBMC which were subsequently separated from other blood products by Ficoll hypaque density gradient centrifugation as described previously. ${ }^{26}$ Viability of PBMC was consistently $>95 \%$. To assess antigen specific lymphocyte proliferation, $1 \times 10^{6} / \mathrm{ml}$
PBMC were cultured at $37^{\circ} \mathrm{C}$ in $5 \% \mathrm{CO}_{2}$ in 96 well U bottom microplates in a total volume of $200 \mu \mathrm{l}$ for three days either alone or in the presence of OKT3 (1:50 dilution), PHA (10 $\mu \mathrm{g}$ / $\mathrm{ml}), H$ pylori sonicate $(3 \mu \mathrm{g} / \mathrm{ml}$ for PBMC and $300 \mu \mathrm{g} / \mathrm{ml}$ for LPL), NapA $(1 \mu \mathrm{g} / \mathrm{ml})$, AphC $(1 \mu \mathrm{g} / \mathrm{ml})$, recombinant urease $\mathrm{B}$ (rUreB) $(1 \mu \mathrm{g} / \mathrm{ml})$, or $\beta$-galactosidase ( $1 \mu \mathrm{g} / \mathrm{ml})$, essentially as described previously. ${ }^{26}$ Gastric LPL were isolated and used in proliferation studies as previously described.$^{26}$ The optimal stimulatory concentration for each recombinant antigen was predetermined for both recombinant NapA and AphC (range $0.05-3 \mu \mathrm{g} / \mathrm{ml}$ ) using samples of PBMC and LPL obtained from $H$ pylori infected $(\mathrm{n}=4)$ and uninfected individuals $(\mathrm{n}=4)$ and in both cases was found to be $1 \mu \mathrm{g} / \mathrm{ml}$ (data not shown).

\section{Measurement of IFN- $\gamma$ and IL- 10 secretion by PBMC and LPL}

PBMC $\left(1 \times 10^{6} / \mathrm{ml}\right)$ and LPL $\left(4 \times 10^{5} / \mathrm{ml}\right)$ were cultured either alone or in the presence of the antigens described above for three days at $37^{\circ} \mathrm{C}$ in $5 \% \mathrm{CO}_{2}$. The culture supernatants were collected and stored at $-80^{\circ} \mathrm{C}$ prior to quantifying the amounts of IFN- $\gamma$ and IL-10 present using commercially available ELISA kits (Cambridge Bioscience, UK).

\section{Statistical analysis}

The significance of the difference between the results obtained with $H$ pylori positive and $H$ pylori negative individuals was evaluated using the Mann-Whitney U test/ Wilcoxon and independent Student's $t$ test.

\section{RESULTS}

\section{Immunoblotting of serum obtained from $\mathrm{H}$ pylori infected and uninfected subjects}

Cohorts of sera obtained from $H$ pylori infected and uninfected individuals were screened for anti- $H$ pylori IgG antibodies by western blotting. All of the $H$ pylori infected individuals examined recognised a heterogeneous population of $H$ pylori antigens (fig lA). Similarly, sera obtained from subjects known to be uninfected were found to be immunoreactive against $H$ pylori antigens but to a lesser extent (fig 1B compared with fig 1A). The anti-H pylori immunoreactivity of sera from both infected and uninfected cohorts was immunodepleted almost completely only by pre-adsorption of the sera with whole $H$ pylori extracts (fig 2, lane $\mathrm{Hp}$ in all panels). Adsorption of the same sera with $C$ jejuni resulted in some but considerably less immunodepletion compared with adsorption with $H$ pylori, and very little was seen when the samples were adsorbed with $E$ aerogenes, $S$ typhimurium, or $Y$ pseudotuberculosis (fig 2). Also, the ability of rabbit polyclonal 


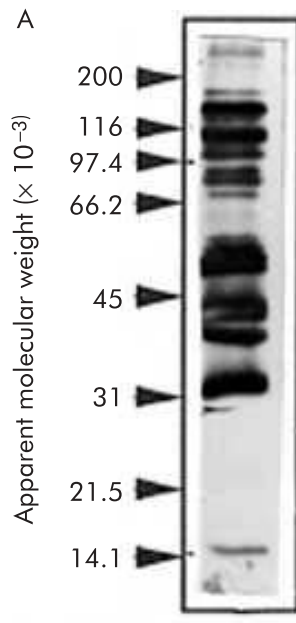

1

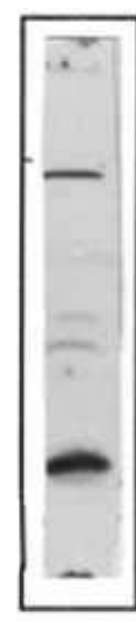

2

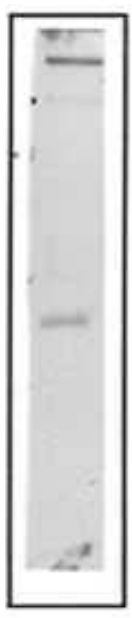

3
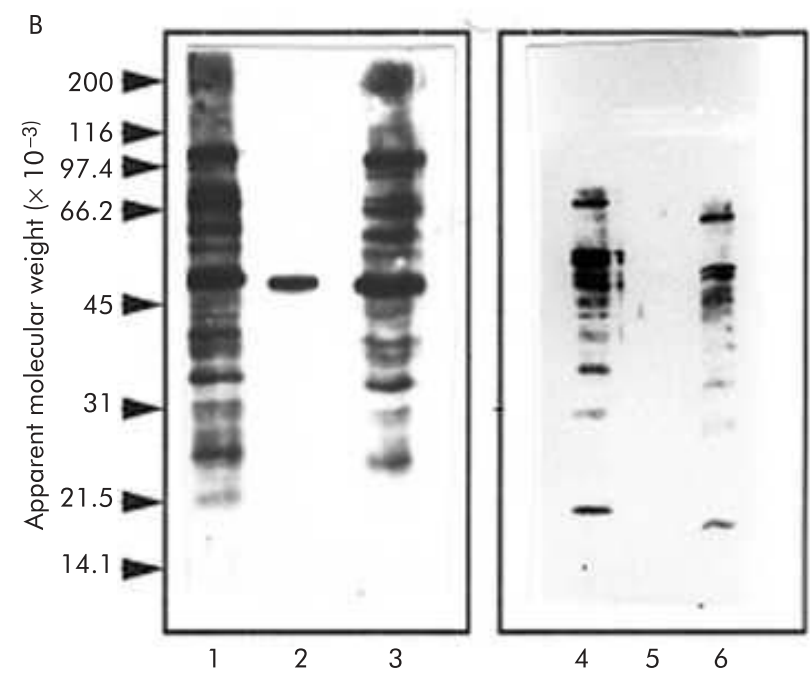

Figure $3 C$ jejuni and $E$ coli antigens recognised by anti-Helicobacter pylori antiserum and elimination of cross reactivity by adsorption with $H$ pylori. (A) Western blot of $H$ pylori (lane 1), C jejuni (lane 2), and E coli (lane 3) probed with rabbit anti-H pylori antiserum. A sonicate of each bacterium $(50 \mu \mathrm{g})$ was subjected to sodium dodecyl sulphate-polyacrylamide gel electrophoresis and immunoblotting, as described in the methods section. (B) Effect of adsorbing serum obtained from a $\mathrm{H}$ pylori infected subject (lanes 1-3) and a subject negative for $H$ pylori (lanes 4-6) with E coli (lanes 1 and 4), $H$ pylori (lanes 2 and 5), or $C$ jejuni (lanes 3 and 6).

anti-whole $H$ pylori antiserum to cross react with $C$ jejuni and $E$ coli antigens was examined by western blotting (fig 3A). Anti- $H$ pylori antiserum recognised a reduced number of antigens on both $E$ coli and $C$ jejuni compared with $H$ pylori itself. Specifically, the antiserum recognises proteins of molecular mass 72, 50, 40, 36, and $25 \mathrm{kDa}$ on $C$ jejuni and proteins of molecular mass 200, 116, 45, and $38 \mathrm{kDa}$ on $E$ coli (fig 3A). Of these, only three proteins ( 70 and $25 \mathrm{kDa}$ from $C$ jejuni and $200 \mathrm{kDa}$ from $E$ coli) showed pronounced cross reactivity. Additional adsorption experiments demonstrated that $E$ coli also failed to significantly deplete anti- $H$ pylori seroreactivity (fig 3B).

\section{Identification of two antigens recognised by serum from $H$ pylori negative subjects}

Preparative continuous elution SDS-PAGE was used to fractionate whole $H$ pylori on the basis of molecular size.

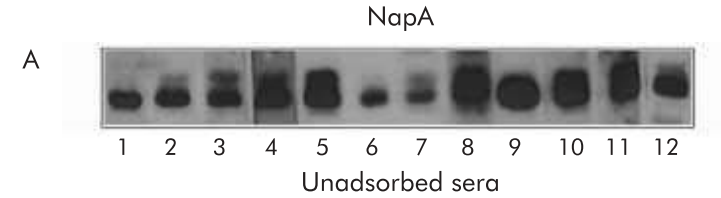

B

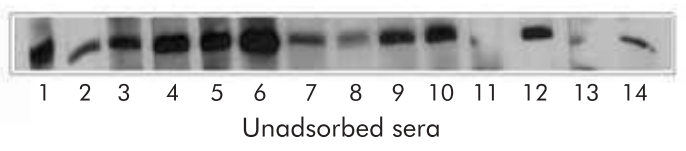

C
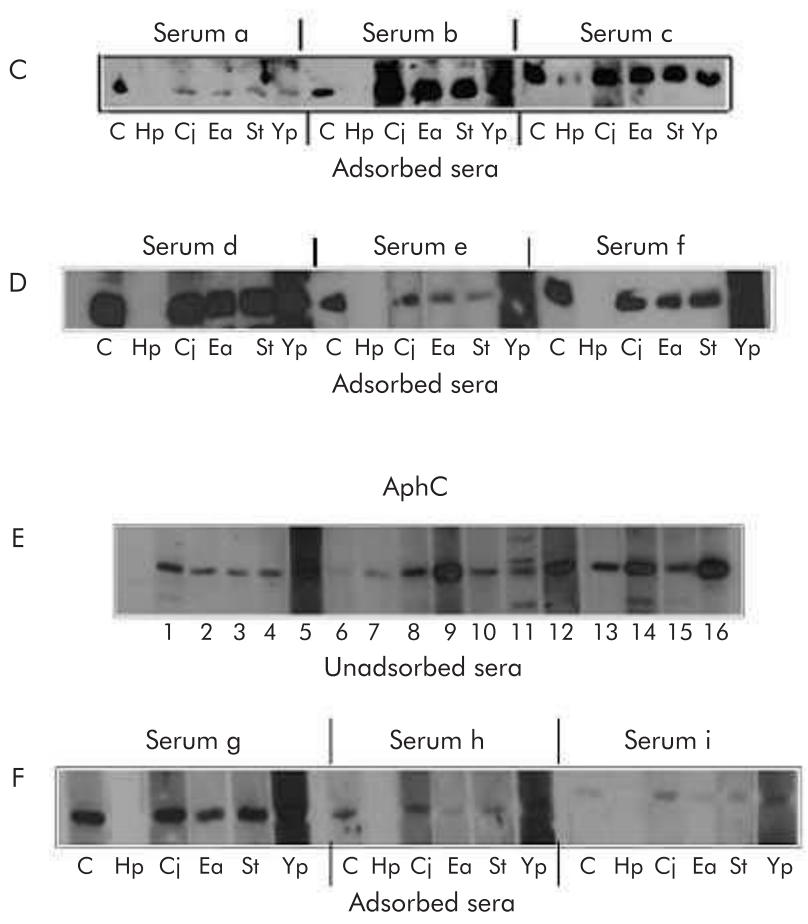

Figure 4 Immunoreactivity of neutrophil activating protein (NapA) and alkyl hydroperoxide reductase (AphC) with sera from uninfected seropositive subjects. Untreated sera (1/50) were used to probe blots of recombinant NapA (A, B) or AphC (E). Selected sera from these individuals were also adsorbed with the bacterial sonicates described in the legend to fig 2, prior to probing blots of $\operatorname{NapA}(C$, three sera and D, three sera) or AphC (F, four sera). The blots were processed as described in fig 2.

Two immunoreactive antigens were identified by probing immunoblots of protein fractions with serum from $H$ pylori uninfected individuals. $\mathrm{N}$ terminal amino acid sequencing of two of the seroreactive antigens revealed one to be NapA and the other, AphC. Recombinant forms of both antigens were subsequently generated and used for further studies. Almost all sera from uninfected subjects had IgG that reacted with both recombinant NapA (fig 4A, B) and AphC (fig 4E). Furthermore, this immunoreactivity was completely depleted only when the sera were pre-adsorbed with $H$ pylori. Some immunoreactivity against NapA (fig 4C, D) and AphC (fig 4F) appears to be adsorbed partially, but incompletely, by other bacteria.

\section{IgG subclass responses to Nap A and AphC}

Both total IgG and IgG subclass responses to $H$ pylori recombinant NapA and AphC were analysed in sera from $H$ pylori infected and uninfected individuals by ELISA. IgG immunoglobulins to NapA and AphC were present in the serum of both $H$ pylori positive and $H$ pylori negative subjects (fig 5A, B). Interestingly, $H$ pylori negative individuals had a 

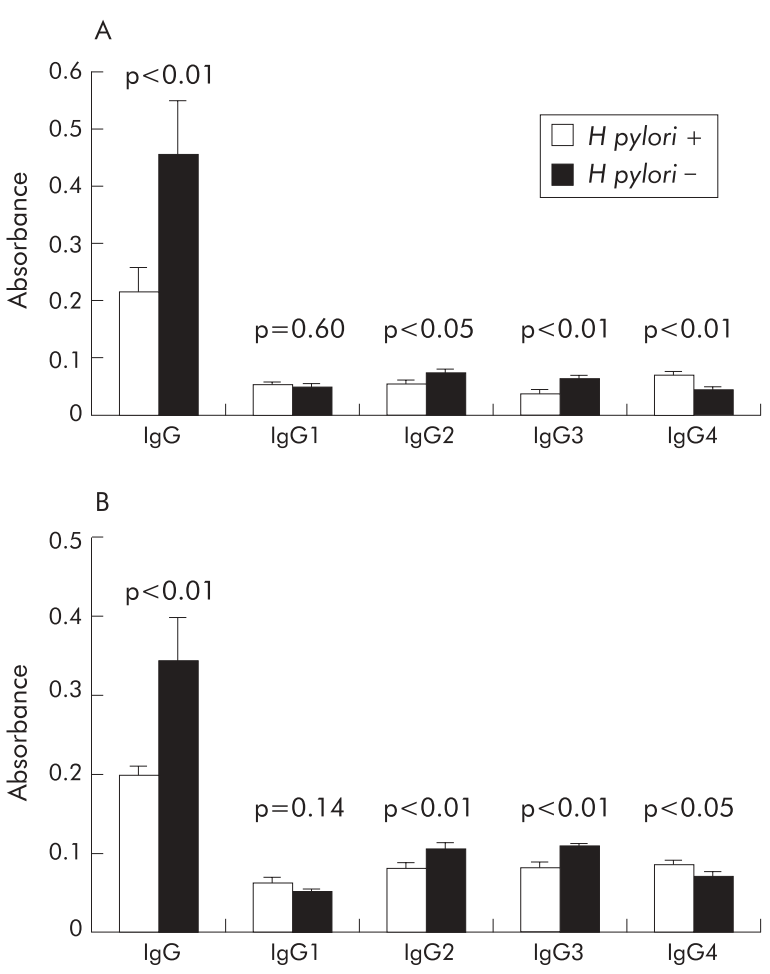

Figure 5 Total $\lg G$ and $\lg G$ subclass responses to neutrophil activating protein (NapA) and alkyl hydroperoxide reductase (AphC). Total lgG response and the various $\lg G$ subclass responses to NapA (A) and AphC (B) in serum obtained from Helicobacter pylori positive and $\mathrm{H}$ pylori negative individuals are shown. IgG levels were determined by ELISA, as described in the methods section and the absorbance axes represent readings obtained at $450 \mathrm{~nm}$ for total lgG and $405 \mathrm{~nm}$ for the lgG subclasses.

significantly greater total IgG response to both NapA $(\mathrm{p}<0.01)$ and AphC $(\mathrm{p}<0.01)$ compared with the infected cohort. Analysis of the subclass specificity of the IgG response to NapA demonstrated that uninfected subjects had a significantly higher IgG2 $(\mathrm{p}<0.05)$ and IgG3 response $(p<0.01)$ whereas the infected cohort had a higher IgG4 response $(\mathrm{p}<0.01)$ (fig $5 \mathrm{~A})$. A similar pattern was seen in the subclass responses to AphC (fig 5B). There were no significant differences in the IgGl responses to these antigens in either study group.

Proliferative responses of PBMC and LPL to NapA and AphC The proliferative responses of PBMC to NapA, AphC, and $H$ pylori sonicate (HPS) were significantly higher $(\mathrm{p}<0.05$ in all three cases) in $H$ pylori negative compared with $H$ pylori positive subjects (fig 6A). In contrast, the proliferative responses to rUreB were not significantly different between $H$ pylori positive $(\mathrm{n}=10)$ and $H$ pylori negative $(\mathrm{n}=10)$ patients. Similarly, the proliferative responses of LPL to NapA, AphC, and HPS were significantly higher $(\mathrm{p}<0.05$ in all three cases) in $H$ pylori negative compared with $H$ pylori positive patients (fig 6B) whereas there were no significant differences between the two cohorts in the proliferative responses observed to rUreB. No significant differences were found between the two groups after stimulation with PHA, OKT3, or $\beta$-galactosidase (table 1). $\beta$-Galactosidase was included as a control histidine tagged fusion protein.

\section{Induction of IFN- $\gamma$ and IL- 10 production by $H$ pylori HPS, NapA, AphC, and rUreB in PBMC and LPL} Human PBMC and LPL were incubated with NapA, AphC, rUreB, and HPS to determine the effect of these antigens on
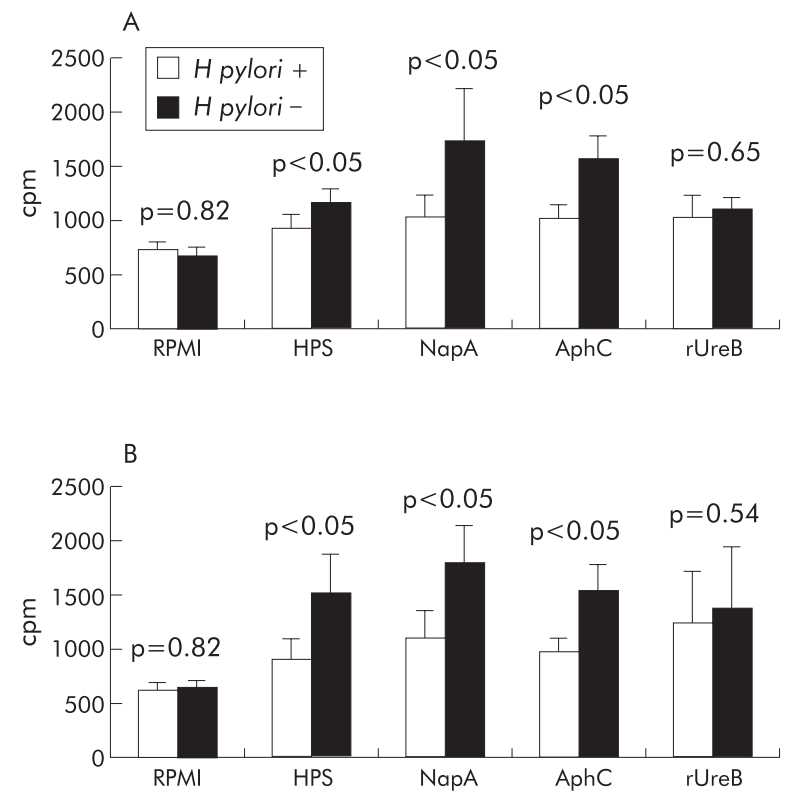

Figure 6 Proliferative responses of peripheral blood mononuclear cells (PBMC) and lamina propria lymphocytes (LPL) to neutrophil activating protein (NapA) and alkyl hydroperoxide reductase (AphC). The proliferative responses of PBMC (A) and LPL (B) to Helicobacter pylori sonicate (HPS) ( $3 \mu \mathrm{g} / \mathrm{ml}$ for PBMC and $300 \mu \mathrm{g} / \mathrm{ml}$ for LPL), NapA $(1 \mu \mathrm{g} / \mathrm{ml})$, AphC $(1 \mu \mathrm{g} / \mathrm{ml})$, and recombinant urease B subunit (rUreB) $(1 \mu \mathrm{g} / \mathrm{ml})$ are shown for both $H$ pylori positive $H$ pylori uninfected subjects. Results are expressed as [ $\left.{ }^{3} \mathrm{H}\right]$-thymidine incorporation (cpm) into PBMC $\left(2 \times 10^{6} / \mathrm{ml}\right)$ and LPL $\left(4 \times 10^{5} / \mathrm{ml}\right)$ cultured for three days in the presence of the indicated antigens. All samples were measured in triplicate.

cytokine production. IFN- $\gamma$ production by PBMC from $H$ pylori negative patients stimulated with either NapA $(\mathrm{p}<0.05)$, AphC $(\mathrm{p}<0.01)$, or HPS $(\mathrm{p}<0.05)$ was significantly higher compared with $H$ pylori positive patients (fig 7A). In contrast, PBMC from $H$ pylori positive subjects produced significantly more IL-10 when activated with either NapA $(\mathrm{p}<0.05)$, AphC $(\mathrm{p}<0.05)$, or HPS $(\mathrm{p}<0.05)$ compared with $H$ pylori negative patients (fig 8A).

IFN- $\gamma$ production by LPL was significantly higher in the $H$ pylori negative cohort after stimulation with NapA $(\mathrm{p}<0.0001)$, AphC $(\mathrm{p}<0.01)$, or HPS $(\mathrm{p}<0.05)$ compared with $H$ pylori positive individuals (fig 7B). IL-10 production by LPL was significantly higher in the $H$ pylori positive group after stimulation with NapA $(\mathrm{p}<0.05)$, AphC $(\mathrm{p}<0.05)$, or HPS $(\mathrm{p}<0.05)$ compared with the $H$ pylori negative group (fig $8 \mathrm{~B})$.

Of note, NapA and AphC induced significantly higher IFN $-\gamma$ production by both PBMC and LPL from $H$ pylori negative subjects when compared with rUreB.

\section{DISCUSSION}

Eradication of $H$ pylori is thought to be a rare event once colonisation is established, yet there are indications in the literature that this does occur. ${ }^{13-19}$ Given the high incidence of $H$ pylori infection in the broad population it is likely that some individuals eliminate the infection without intervention. This is a contentious issue however but one that may have implications relating to the actual incidence of exposure as many such individuals would remain seropositive but undetected. Moreover, in many instances, $H$ pylori negative individuals are classified as such based solely on serological EIA, a technique prone to error. ${ }^{27}{ }^{28}$ In addition, cross reactivity with other bacterial species decreases specificity (for example, see Feldman and colleagues ${ }^{29}$ ). More sensitive 
Table 1 Proliferative responses of PBMC and LPL to PHA, OKT3, and $\beta$-galactosidase: $\left[{ }^{3} \mathrm{H}\right]$-thymidine incorporation $(\mathrm{cpm})$

\begin{tabular}{|c|c|c|c|c|c|c|}
\hline & \multicolumn{3}{|l|}{ PBMC } & \multicolumn{3}{|l|}{ LPL } \\
\hline & $\mathrm{HP}+\mathrm{ve}$ & $H P-v e$ & $\mathrm{p}$ Value & $\mathrm{HP}+\mathrm{ve}$ & $H P-v e$ & p Value \\
\hline PHA & 20574 (3974) & $25645(4735)$ & 0.14 & $8378(2086)$ & 7360 (1744) & 0.34 \\
\hline OKT3 & $10112(2318)$ & $12556(2166)$ & 0.31 & 5475 (666) & 4745 (1043) & 0.56 \\
\hline$\beta$-gal & $651(110)$ & $670(124)$ & 0.39 & 601 (165) & 605 (173) & 0.96 \\
\hline
\end{tabular}

HP, Helicobacter pylori; PBMC, peripheral blood mononuclear cells; LPL, lamina propria lymphocytes; $\beta$-gal, $\beta$-galactosidase.

Results are expressed as $\left[{ }^{3} \mathrm{H}\right]$-thymidine incorporation $(\mathrm{cpm})$ into PBMC and LPL cultured for three days. LPL $\left(4 \times 10^{5} / \mathrm{ml}\right)$ were cultured with autologous irradiated $(2500 \mathrm{rads})$ PBMC $\left(2 \times 10^{6} / \mathrm{ml}\right)$ in the presence of IL-2 $(2 \mathrm{IU} /$ $\mathrm{ml})$. All samples were measured in triplicate and are shown as mean $(S E M)(n=30)$. PHA was used at a concentration of $10 \mu \mathrm{g} / \mathrm{ml}$ and $5 \mu \mathrm{g} / \mathrm{ml}$ for PBMC and LPL, respectively. OKT3 was used at a dilution of 1:50 and $\beta$-galactosidase was $1 \mu \mathrm{g} / \mathrm{ml}$.

detection techniques such as immunoblotting combined with enhanced chemiluminescence ${ }^{30}$ facilitate detection of low levels of specific antibodies not detected by ELISA. ${ }^{31-33}$ Additionally, immunoblotting has enabled investigators to differentiate between age related changes in antigen recognition. ${ }^{34-36}$

An antibody response to bacterial antigens is one indicator of prior exposure to an organism. Infection with $H$ pylori at a subclinical level and consequent elimination of the infection has been proposed to account for serological recognition of $H$ pylori antigens in some uninfected subjects. ${ }^{37}$ In this study, we showed that $H$ pylori uninfected subjects had circulating antibodies (IgG) to several $H$ pylori antigens, including NapA and AphC. Immunodepletion and cross reactivity studies indicated that the IgG response was $H$ pylori directed as seroreactivity could only be substantially eliminated by
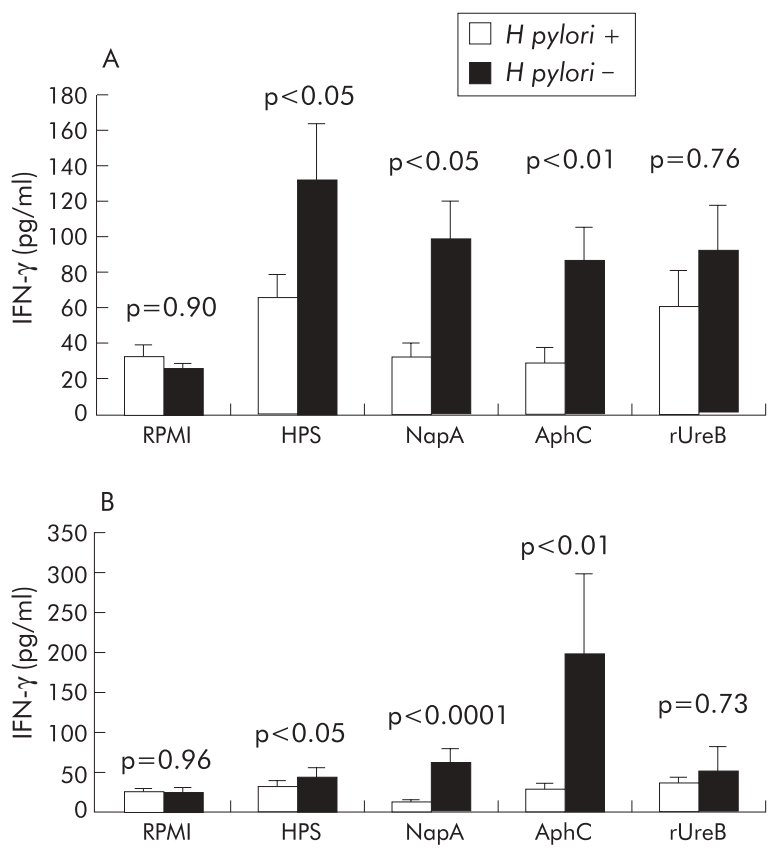

Figure 7 Interferon $\gamma($ IFN- $\gamma$ ) production by peripheral blood mononuclear cells (PBMC) and lamina propria lymphocytes (LPL) in response to neutrophil activating protein (NapA) and alkyl hydroperoxide reductase (AphC). IFN- $\gamma$ production by PBMC (A) and LPL (B) obtained from Helicobacter pylori positive or $\mathrm{H}$ pylori negative individuals in response to the indicated antigens. All antigens were used at $1 \mu \mathrm{g} / \mathrm{ml}$. Supernatants were collected from cultured PBMC and LPL after 72 hours and stored at $-80^{\circ} \mathrm{C}$. IFN- $\gamma$ was measured in the supernatant by ELISA. All samples were measured in duplicate. Results are expressed as mean (SEM). rUreB, recombinant urease B subunit; HPS, $H$ pylori sonicate. adsorption with $H$ pylori but not with $C$ jejuni, $E$ coli, $E$ aerogenes, $S$ typhimurium, or $Y$ pseudotuberculosis. Specific polyclonal antisera (rabbit) to $H$ pylori only reacted weakly with $C$ jejuni and $E$ coli. Similarly, others have demonstrated little cross reactivity with anti-H pylori serum and other prokaryotes (Streptococcus sanguis, Salmonella typhimurium, Campylobacter fetus, Nesseria meningitidis, Haemophilius influenzae, Staphylococcus aureus, and Yersinia enterocolitica). ${ }^{17}{ }^{38}$ It is not possible however to exclude cross reactivity with other gastrointestinal commensals given the many hundreds of such organisms inhabiting the gastrointestinal tract. However, the $H$ pylori directed specificity of the anti-NapA and anti-AphC IgG response is supported by the inability of other bacteria, including $C$ jejuni, to immunodeplete NapA and AphC antibodies from uninfected patient sera, even
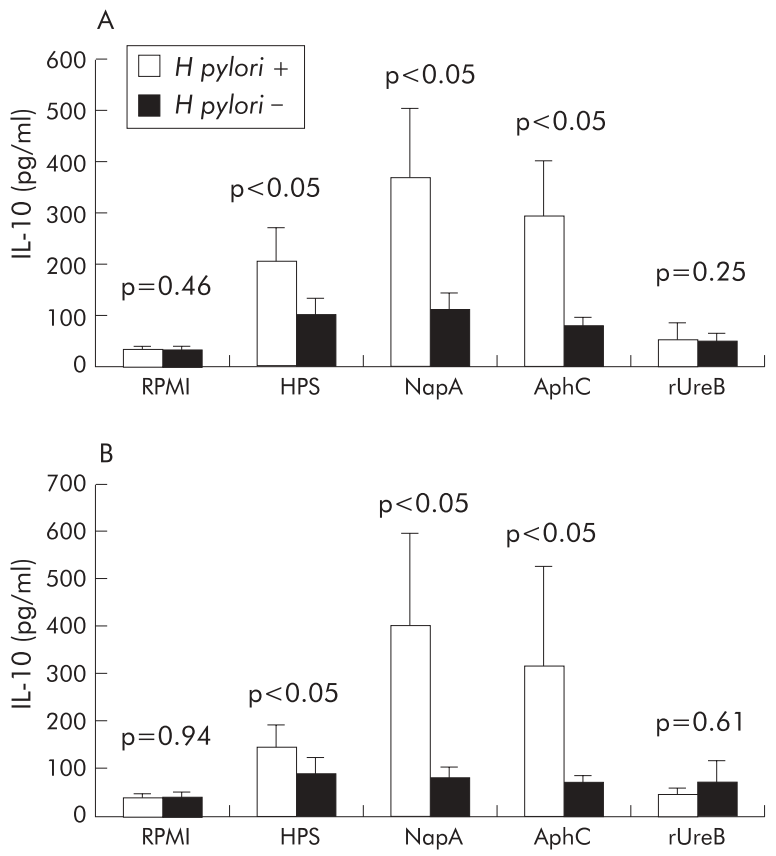

Figure 8 Interleukin $10(\mathrm{IL}-10)$ production by peripheral blood mononuclear cells (PBMC) and lamina propria lymphocytes (LPL) in response to neutrophil activating protein (NapA) and alkyl hydroperoxide reductase (AphC). Levels of IL-10 produced by PBMC (A) and LPL (B) from $H$ pylori positive and $H$ pylori negative subjects in response to the antigens indicated are shown. All antigens were used at $1 \mu \mathrm{g} / \mathrm{ml}$. Supernatants were collected from cultured PBMC and LPL after 72 hours and stored at $-80^{\circ} \mathrm{C}$. IL- 10 was measured in the supernatant by ELISA. All samples were determined in duplicate. Results were expressed as mean (SEM). rUreB, recombinant urease B subunit; HPS, $H$ pylori sonicate. 
though homologues of AphC and NapA from $C$ jejuni exhibit the highest degree of identity to $H$ pylori AphC and NapA, at $67 \%$ and $38 \%$, respectively.

As prospective data were not available for this study there is an inherent uncertainty in unequivocally ascribing the observed antibody responses to $H$ pylori to a high incidence of prior exposure to the bacterium. Although spontaneous eradication/transient colonisation of $H$ pylori infection has been documented in paediatric populations ${ }^{14} 161^{19}$ 39-42 $^{30}$ it is thought to be a less frequent event in adults, yet a significant rate $(7.7 \%)$ of IgG seroreversion was found in a young and middle aged Danish population. ${ }^{8}$ Others too have detected anti-H pylori antibodies in uninfected individuals by immunoblotting (for example, see Nilsson and colleagues ${ }^{43}$ ). One possible explanation for seroreversion in the absence of therapeutic intervention is the widespread use of antimicrobials for other infections with secondary clearance of $H$ pylori. However, there is evidence to suggest that this is unlikely to account for all cases of apparent spontaneous eradication. ${ }^{44} 45$ Strain variation, host genetic factors, and gastric atrophy have also been proposed to account for some cases of seroreversion. ${ }^{46-49}$

In addition to antibody responses, both the proliferative and cytokine responses of NapA and AphC stimulated PBMC and LPL were influenced by the infection status of the individuals. Both the gastric and peripheral lymphoproliferative responses of the uninfected seropositive group were significantly greater than those observed for infected individuals in response to NapA, AphC, HPS, but not rUreB. Furthermore, NapA, AphC, and HPS activated but not rUreB treated PBMC and LPL from uninfected subjects secreted significantly more IFN- $\gamma$ than infected subjects, observations that are similar to previous studies with various preparations and extracts of $H$ pylori..$^{26} 51$ Others too have shown that gastric biopsy samples from uninfected dyspeptic patients have more IFN- $\gamma$ secreting $\mathrm{T}$ cells than infected samples, suggesting that IFN- $\gamma$ type responses might be protective. ${ }^{52} \mathrm{~A}$ number of groups have also reported suppressed lymphocyte responses from infected subjects compared with negative controls, ${ }^{26} 5051$ possibly due to an altered $\mathrm{T}$ cell response secondary to infection or, alternatively, the production of immunosupressive factor(s) by the pathogen. This is in agreement with our present data showing preferential IL-10 secretion by infected individuals.

Finally, as the cytokine profile during infection is documented to play a regulatory role with respect to immunoglobulin production, including subclass and isotype switching, it was of interest to determine the NapA and AphC specific IgG subclass pattern in $H$ pylori infected and uninfected subjects. Both NapA and AphC preferentially, but not exclusively, elicited a stronger $\operatorname{IgG} 3$ response in uninfected subjects and a significantly stronger IgG4 response in $H$ pylori positive individuals. Secretion of IgG4 by human PBMC is known to be suppressed by IFN- $\gamma$ in vitro $^{53}$ but enhanced by IL-10, ${ }^{54}$ a major regulatory cytokine. Studies on various infections including Lyme disease, ${ }^{55}$ rubella $^{56}{ }^{57}$ and mumps ${ }^{58}$ indicate a close association between IFN- $\gamma$ and IgG3 production. Furthermore, the potent opsonising and complement fixing properties of IgG3 have prompted speculation that IgG3 positivity may play a role in disease resolution, particularly in the case of Lyme borreliosis. In this regard it is interesting to note in this study that $H$ pylori negative subjects displayed a predominantly $\mathrm{T}$ helper l-like cytokine and antibody response to NapA and AphC. However, it appears likely that the IgG subclass distribution will be influenced by the biochemical/antigenic properties of the molecules based on the antigen specific cytokine profiles observed in this present and other studies.
In summary, these findings may have implications with regard to protective immunity. In animal studies NapA has been identified as a protective vaccine ${ }^{59}$ and it will be of interest to determine whether AphC demonstrates similar properties.. However, identification of different immune responses to $H$ pylori antigens in $H$ pylori negative and positive populations suggests that the nature of the immune response to $H$ pylori exposure may have an influence on patient/disease outcome.

\section{ACKNOWLEDGEMENTS}

The authors acknowledge Professor D Weir for the biopsy material, Dr A Moran and John Ferris for C jejuni and Dr Ken Whelan for various samples of gut flora. This work was supported by a Health Research Board grant (YSA).

\section{Authors' affiliations}

H J Windle*, Y S Ang*‡, V A Morales, R McManus*, D Kelleher, Department of Clinical Medicine and Dublin Molecular Medicine Centre, Trinity Centre for Health Sciences, St James's Hospital, Dublin, Ireland

*H J Windle, Y S Ang, and R McManus contributed equally to the study. $\ddagger$ Present address: Department of Gastroenterology, Royal Albert Edward Infirmary, Wigan, Manchester WN1 2NN, UK.

\section{REFERENCES}

1 Marshall BJ. Unidentified curved bacilli on the gastric epithelium in active chronic gastritis. Lancet 1983:l:1273-5.

2 Marshall BJ, Warren JR. Unidentified curved bacilli in the stomach of patients with gastritis and peptic ulceration. Lancet 1984;1:1311-15.

3 Bayerdorffer E, Neubauer A, Rudolph B, et al. Regression of primary gastric lymphoma of mucosa-associated lymphoid tissue type after cure of Helicobacter pylori infection. MALT Lymphoma Study Group. Lancet 1995;345:1591-4

4 Blaser MJ, Parsonnet J. Parasitism by the "slow" bacterium Helicobacter pylori leads to altered gastric homeostasis and neoplasia. J Clin Invest 1994;94:4-8.

5 Ernst PB, Pecquet S. Interactions between Helicobacter pylori and the local mucosal immune system. Scand J Gastroenterol 1991;187:56-64.

6 Rathbone BJ, Wyatt JI, Worsley BW, et al. Systemic and local antibody responses to gastric Campylobacter pyloridis in non-ulcer dyspepsia. Gut 1986;27:642-7.

7 Andersen LP, Rosenstock SJ, Bonnevie O, et al. Seroprevalence of immunoglobulin $G, M$ and $A$ antibodies to $H$. pylori in an unselected Danish population. Am J Epidemiol 1996;143:1157-64.

8 Rosenstock S, Jorgensen T, Andersen L, et al. Seroconversion and seroreversion in $\lg G$ antibodies to $H$. pylori: a serology based prospective cohort study. J Epidemiol Community Health 2000;54:444-50.

9 Mitchell HM, Bohane TD, Berkowicz J, et al. Antibody to Campylobacter pylori in families of index children with gastrointestinal illness due to $C$ pylori. Lancet 1987;2:681-2

10 Von Wulffen H, Grote HJ Enzyme linked immunosorbent assay for detection of immunoglobulins $A$ and $G$ antibodies to Campylobacter pylori. Eur J Clin Microbiol Infect Dis 1988;7:559-65.

11 Glupczynski Y, Burette A, Goosens H, et al. Effects of antimicrobial therapy on the specific serological response to Helicobacter pylori infection. Eur J Clin Microbiol Infect Dis 1992;11:583-8.

12 Langenberg W, Rauws EA, Houthoff HJ, et al. Follow-up study of individuals with untreated Campylobacter pylori-associated gastritis and of noninfected persons with non-ulcer dyspepsia. J Infect Dis 1988;157:1245-9.

13 Granstrom M, Tindberg Y, Blennow M. Seroepidemiology of Helicobacter pylori infection in a cohort of children monitored from 6 months to 11 years of age. J Clin Microbiol 1997;35:468-70.

14 Perri F, Pastore, M, Clemente R, et al. Helicobacter pylori infection may undergo spontaneous eradication in children: a 2-year follow-up study. J Pediatr Gastroenterol Nutr 1998;27:181-3.

$15 \mathrm{Xia} \mathrm{HH}$, Talley NJ. Natural acquisition and spontaneous elimination of Helicobacter pylori infection: clinical implications. Am J Gastroenterol 1997;92:1780-7

16 Klein PD, Gilman RH, Leon-Barua R, et al. The epidemiology of Helicobacter pylori in Peruvian children between 6 and 30 months of age. Am J Gastroenterol 1994;89:2196-200.

17 Meyer B, Werth B, Beglinger C, et al. Helicobacter pylori infection in healthy people: a dynamic process? Gut 1991;32:347-50.

18 Torres J, Perez-Peres G, Goodman KJ, et al. A comprehensive review of the natural history of Helicobacter pylori infection in children. Arch Med Res 2000;31:431-69

19 Malaty HM, El-Kasabany A, Graham DT, et al. Age at acquisition of H. pylori infection: a follow-up study from infancy to adulthood Lancet 2002;359:931-5.

20 Marshall BJ, Armstrong JA, McGechie DB, et al. Attempt to fulfil Koch's postulates for pyloric Campylobacter. Med J Aust 1985; 142:436-9. 
21 Morris A, Nicholson G. Ingestion of Campylobacter pyloridis causes gastritis and raised fasting gastric $\mathrm{pH}$. Am J Gastroenterol 1987;82:192-9.

22 Towbin H, Staehelin T, Gordon J. Electrophoretic transfer of proteins from polyacrylamide gels to nitrocellulose sheets: procedure and some applications. Proc Natl Acad Sci U S A, 1979;76:4350-4.

23 Laemmli UK. Cleavage of structural proteins during the assembly of the head of bacteriophage T4. Nature 1970;227:680-5.

24 Silhavy TJ, Berman ML, Enquist LW. Experiments with gene fusions. Cold Spring Harbour: Cold Spring Harbour Laboratory Press, 1984.

25 Don RH, Cox PT, Wainwright BJ, et al. 'Touchdown' PCR to circumvent spurious priming during gene amplification. Nucleic Acids Res 1989;19:4008.

26 Fan XJ, Chua A, Shahi CN, et al. 1994. Gastric T lymphocyte responses to Helicobacter pylori in patients with $\mathrm{H}$ pylori colonisation. Gut 1994;35:1379-81.

27 Cockburn M, Cow B. The effect of measurement error on the determination of H. pylori prevalence. Epidemiology 1997;8:205-9.

28 Pearce DC, Peach HG, Farish SJ. H. pylori antibody titres in serum, plasma, and successively thawed specimens: implications for epidemiological studies, J Clin Pathol 1996:49:1017-19.

29 Feldman RA, Deeks JJ, Evans SJW, the H. pylori Serology Study Group. Multilaboratory comparison of eight commercially available H. pylori serology kits. Eur J Microbiol Infect Dis 1995; 14:428-33.

30 Durrant I, Fowler S. Chemiluminescent detection systems for protein blotting. In: Dunbar BS, ed. Protein blotting: A practical approach. New York: IRL Press, 1994:141-52.

31 Nilsson I, Ljungh A, Aleljung $P$, et al. Immunoblot assay for serodiagnosis of Helicobacter pylori infections. J Clin Microbiol 1997;35:427-32.

32 Nilsson I, Lindkvist $\mathrm{P}$, Wretlind $\mathrm{B}$, et al. Immunoblots are superior to EIA for anti-H. pylori antibody determinations in young children from both high and low endemic areas. Gut 1999;45(suppl 111):A97.

33 Rocha GA, Oliveira AM, Queiroz DM, et al. Immunoblot analysis of humoral immune response to Helicobacter pylori in children with and without duodena ulcer. J Clin Microbiol 2000;38:1777-81.

34 Mitchell HM, Hazell SL, Kolesnikow T, et al. Antigen recognition during progression from acute to chronic infection with a cagA-positive strain of Helicobacter pylori. Infect Immun 1996;64:1166-72.

35 Westblom TU, Madan E, Gudipati S, et al. Diagnosis of Helicobacter pylori infection in adult and pediatric patients by using Pyloriset, a rapid latex agglutination test. J Clin Microbiol 1992;30:96-8.

36 Chmiela M, Lawnik M, Czkwianianc E, et al. Systemic humoral responses to $\mathrm{H}$. pylori in children and adults. Arch Immunol Ther Exp 1998:46:161-7.

37 Yamaguchi $\mathrm{H}$, Osaki $\mathrm{T}$, Kai $\mathrm{M}$, et al. Immune response against a crossreactive epitope on the heat shock protein 60 homologue of Helicobacter pylori. Infect Immun 2000;68:3448-54.

38 Espersen F. Immunoglobulin $G$ antibodies to Helicobacter pylori in patients with dyspeptic symptoms investigated by the western immunoblot technique. J Clin Microbiol 1992;30:1743-51.

39 Mahalanabis D, Rahman MM, Sarker SA, et al. 1996. H. pylori infection in the young in Bangladesh: prevalence, socio-economic and nutritional aspects. Int J Epidemiology 1996;25:894-8.

40 Granstrom M, Tindberg Y, Blennow M. Seroepidemiology of H. pylori infection in a cohort of children monitored from 6 months to 11 years of age. J Clin Microbiol 1997;35:468-70.
41 Thomas JE, Dale A, Harding $M$, et al. H. pylori colonization in early life. Pediatr Res 1995;45:218-23.

42 Perez-Perez GI, Sack RB, Reid R, et al. Transient and persistent H. pylori colonization in native American children. J Clin Microbiol 2003:41:2401-7.

43 Nilsson $\mathrm{N}$, Liungh $\mathrm{A}$, Aleljung $\mathrm{P}$, et al. Immunoblot assay for serodiagnosis of H. pylori infections. J Clin Microbiol 1997;35:427-32.

44 Rothenbacher D, Bode G, Adler G, et al. Use of commonly prescribed antibiotics is not associated with prevalence of $H$. pylori infections in adults. Scand J Gastroenterol 1997;32:1096-9.

45 Leung W-K, Hung L, Kwok C, et al. Follow up of serial urea breath test results in patients after consumption of antibiotics for non gastic infections. World J Gastroenterol 2002;8:703-6.

46 Kuipers EJ, Klinkenberg-Knol EC, Vandenbroucke-Grauls CMEJ, et al. Role of $\mathrm{H}$. pylori in the pathogenesis of atrophic gastritis. Scand J Gastroenterol 1997;32(suppl 223):28-34.

47 Kuipers EJ, Uyterlinde AM, Pena AS, et al. Long term sequelae of $\mathrm{H}$. pylori gastritis. Lancet 1995;345:1525-8.

48 Valle J, Kekki M, Sipponen $\mathrm{P}$, et al. Long term course and consequences of $\mathrm{H}$. pylori gastritis. Scand J Gastroenterol 1996;31:546-50.

49 Kokkola A, Kosunen TU, Puolakkainen P, et al. Spontaneous disappearance of $\mathrm{H}$. pylori antibodies in patients with advanced atrophic gastritis. APMIS 2003:111:619-24.

50 Karttunen R. Blood lymphocyte proliferation, cytokine secretion and appearance of $\mathrm{T}$ cells with activation surface markers in cultures with Helicobacter pylori. Comparison of the responses of subjects with and without antibodies to H. pylori. Clin Exp Immunol 1991;83:396-400.

51 Duchmann R, Scherer $\mathrm{H}$, Neurath $M$, et al. Normal interleukin-12 production in individuals with antibodies to Helicobacter pylori. APMIS 1997; 105:824-30

52 Kartunnen R, Kartunnen T, Ekre HP, et al. Interferon gamma and interleukin 4 secreting cells in the gastric antrum in $\mathrm{H}$. pylori positive and negative gastritis. Gut 1995;36:341-5.

53 Sutherland $M$, Blaser K, Pene J. Effects of interleukin-4 and interferon-gamma on the secretion of lgG4 from human peripheral blood mononuclear cells. Allergy 1993;48:504-10.

54 Jeannin $\mathbf{P}$, Lecoanet $S$, Delneste $Y$, et al. $\lg E$ versus $\lg G 4$ production can be differentially regulated by IL-10. J Immunol 1998;160:3555-61.

55 Widhe $M$, Ekerfelt $C$, Forsberg $P$, et al. lgG subclasses in Lyme borreliosis: a study of specific lgG subclass distribution in an interferon-gammapredominated disease. Scand J Immunol 1998;47:575-81.

56 Linde GA. Subclass distribution of rubella virus-specific immunoglobulin G J Clin Microbiol 1985;21:117-21.

57 Nakayama T, Urano T, Osano $M$, et al. Evaluation of live trivalent vaccine of measles AIK-C strain, mumps Hoshino strain and rubella Takahashi strain, by virus-specific interferon-gamma production and antibody response. Microbiol Immunol 1990;34:497-508

58 Linde GA, Granstrom M, Orvell C. Immunoglobulin class and immunoglobulin $G$ subclass enzyme-linked immunosorbent assays compared with microneutralization assay for serodiagnosis of mumps infection and determination of immunity. J Clin Microbiol 1987;25:1653-8.

59 Satin B, Del Giudice G, Della Bianca V, et al. The neutrophil-activating protein (HP-NAP) of Helicobacter pylori is a protective antigen and a major virulence factor. J Exp Med 2000;191:1467-76. 


\section{PostScript}

\section{LETTERS}

\section{ITPA genotyping test does not improve detection of Crohn's disease patients at risk of azathioprine/6-mercaptopurine induced myelosuppression}

The thiopurine drugs azathioprine (AZA) and 6-mercaptopurine (6-MP) are effective for the treatment of inflammatory bowel disease (IBD) and their prescription is increasing. Haematotoxicity, which can lead to potentially life threatening bone marrow suppression, represents the most serious side effect of thiopurine therapy. It has been attributed to the accumulation of active cytotoxic metabolites of AZA/6-MP, collectively called 6-thioguanine nucleotides, resulting from a deficiency in thiopurine catabolism specifically catalysed by the thiopurine $S$-methyltransferase (TPMT) enzyme. Genotyping tests are now available to identify deficient and intermediate methylators who are, respectively, homozygous and heterozygous for non-functional alleles of the TPMT gene. As pointed out by Lennard in the leading article (Gut 2002;51:143-6), it is clear that myelosuppression may be caused by other factors in addition to variable TPMT.

Since the identification of the molecular basis of inosine triphosphate pyrophosphatase (ITPAse) deficiency, ${ }^{1}$ a clinically benign condition characterised by abnormal accumulation of inosine triphosphate in erythrocytes, the possibility of a correlation between thiopurine toxicity and ITPAse deficiency has been raised. Complete ITPase deficiency was found to be associated with a homozygous missense 94C $>$ A mutation that encodes a $\mathrm{Pro}^{32} \mathrm{Thr}$ exchange, whereas an intronic IVS2+21 A $>C$ polymorphism was shown to have a less severe effect, homozygotes retaining $60 \%$ ITPAse activity. It was then postulated that in ITPAse deficient patients treated with thiopurine drugs, a 6-thio-ITP metabolite could accumulate resulting in toxicity. ${ }^{1} \mathrm{~A}$ recent study in 62 patients with inflammatory bowel disease reported a significant association between the ITPA $94 \mathrm{C}>\mathrm{A}$ polymorphism and AZA related adverse effects, specifically flu-like symptoms, rash, and pancreatitis. $^{2}$ No correlation was observed with occurrence of neutropenia but only 11 patients were studied. We previously reported TPMT genotype analysis in 41 Crohn's disease

Table 1 Distribution of ITPA genotypes in 41 Crohn's disease (CD) patients and 100 healthy Caucasians

\begin{tabular}{lcl}
\hline ITPA genotype & CD patients $(n=41)$ & Control populationt $(\mathbf{n}=100)$ \\
\hline$W_{t} / W_{t}$ & $26(0.63)^{*}$ & $64(0.64)$ \\
$W_{t} / 94 C>A$ & $6(0.15)$ & $10(0.10)$ \\
$W_{t} / I V S 2+21 A>C$ & $7(0.17)$ & $24(0.24)$ \\
$94 C>A / 94 C>A$ & $0(0.00)$ & $0(0.00)$ \\
IVS2+21A $>C / I V S 2+21 A>C$ & $1(0.02)$ & $0(0.00)$ \\
$94 C>A / I V S 2+21 A>C$ & $1(0.02)$ & $2(0.02)$ \\
\hline
\end{tabular}

*Values in parentheses represent genotype frequencies.

†The control population comprised 100 healthy Caucasians who were genotyped in a previous study.
(CD) patients who had experienced leucopenia during AZA/6-MP therapy. ${ }^{3}$ Even though this study confirmed the efficiency of TPMT genotyping in identifying patients at risk of developing myelosuppression, it also highlighted its limitations, as only $27 \%$ of patients carried mutant alleles of the TPMT gene that were associated with enzyme deficiency. This prompted us to investigate the occurrence of ITPA mutations in this series of patients in order to evaluate whether genotyping of the ITPAse gene could improve the detection rate of patients at risk of thiopurine myelotoxicity.

Our population comprising $4 \mathrm{l}$ patients with $C D$ has been described in detail previously. ${ }^{3}$ Briefly, all patients had either leucopenia (white blood cell count $<3000$ / $\mathrm{mm}^{3} ; \mathrm{n}=24$ ) or thrombocytopenia (platelets $\left.<100000 / \mathrm{mm}^{3} ; \mathrm{n}=30\right)$, or both $(\mathrm{n}=14)$, leading either to discontinuation of treatment or reduction of dose by $50 \%$ or more during AZA $(\mathrm{n}=33)$ or 6 -MP $(\mathrm{n}=8)$ treatment. Patients were genotyped for the ITPA $94 \mathrm{C}>\mathrm{A}$ and IVS2+21 A $>C$ mutations according to a previously described procedure based on endonuclease digestion of polymerase chain reaction products. ${ }^{1}$ Distribution of the 41 patients according to their ITPA genotype is presented in table 1 and compared with that of a previously published control population of 100 healthy Caucasians. ${ }^{1}$ Allele frequencies in the $\mathrm{CD}$ population were 0.085 for the $94 \mathrm{C}>\mathrm{A}$ mutation and 0.12 for the IVS $2+21 \mathrm{~A}>\mathrm{C}$ mutation, similar to frequencies observed in the control population $(0.06$ and 0.13 , respectively). There was no significant difference in the genotypes distribution between the two populations, which confirmed the lack of association between ITPAse deficiency and myelosuppression during thiopurine therapy. Due to the retrospective nature of the study, no correlation with other side effects could be investigated.

In conclusion, application of ITPA genotyping tests does not seem to improve the identification of patients at risk of myelosuppression with AZA/6-MP therapy. Although we believe that conventional TPMT genotyping tests should still be applied before the initiation of thiopurine treatment, further work is needed on the role of other candidate genes that may be involved in thiopurine haematotoxicity.

\section{Acknowledgements}

We thank $\mathrm{N}$ Ferrari and A Vincent for their assistance in performing the study and the members of the GETAID for recruiting patients in the study.
D Allorge, R Hamdan, F Broly EA2679, Faculté de Médecine/Pôle Recherche, Place de Verdun, Lille, France

C Libersa

Centre d'Investigations Cliniques, Hôpital Cardiologique, CH et U Lille, Lille, France

J-F Colombel

Service d'Hépato-Gastroentérologie, Hôpital Huriez, $\mathrm{CH}$ et $\mathrm{U}$ Lille, Lille, France

Groupe d'Etudes Thérapeutiques des Affections Inflammatoires Digestives (GETAID) Service d'Hépato-Gastroentérologie, Hôpital Saint-Louis, Paris, France

Correspondence to: Professor J-F Colombel, Service d'Hépato-Gastroentérologie, Hôpital Huriez, CH et U Lille, 59037 Lille, France; ifcolombel@chru-lille.fr

doi: $10.1136 /$ gut.2004.055947

Competing Interests: None declared.

\section{References}

1 Sumi S, Marinaki AM, Arenas M, et al. Genetic basis of inosine triphosphate pyrophosphohydrolase deficiency. Hum Genet 2002;111:360-7.

2 Marinaki AM, Ansari A, Duley JA, et al. Adverse drug reactions to azathioprine therapy are associated with polymorphism in the gene encoding inosine triphosphate pyrophosphatase (ITPase). Pharmacogenetics 2004; 14:181-7.

3 Colombel JF, Ferrari N, Debuysere $\mathrm{H}$, et al. Genotypic analysis of thiopurine Smethyltransferase in patients with Crohn's disease and severe myelosuppression during azathioprine therapy. Gastroenterology 2000;118:1025-30.

\section{Small bowel malignancy at diagnosis of coeliac disease}

We were very interested in the paper by Rampertab et al (Gut 2003;52:121-14) and the correspondence by Hawdle et al (Gut 2004;53:470). Their data are quite similar to ours, from the Italian Registry of Complications of Coeliac Disease.

We collected information on 1968 patients over 18 years of age (mean age at diagnosis: 36.7 years; female/male ratio 3:1), diagnosed with coeliac diseases between January 1982 and December 2002 at 20 Italian clinical centres specialised in gastrointestinal disease. The diagnosis was made according to revised ESPGHAN criteria. ${ }^{1}$ We found five $(0.25 \%)$ patients with a small bowel malignancy at the time of diagnosis of coeliac disease. Age range was 49-69 years (mean 59 years) with a predominance of females (4:1). Survival rate was very poor as three patients died within 36 months of diagnosis.

These results indicate that there is an increased risk of developing small bowel malignancy in patients with coeliac disease. This correlation was confirmed by the female/ male ratio. In fact, while small bowel neoplasms are usually more frequent in males, in our population four of five cases were female. Moreover, mean age at diagnosis of these cases was higher than that of patients overall, emphasising that the risk of a neoplasm increases with longstanding coeliac disease. 
In conclusion, early diagnosis of coeliac disease should be made to prevent small bowel neoplasms from developing, and screening for this cancer should be carried out at diagnosis of coeliac disease, especially in patients diagnosed during adulthood.

M Silano, M De Vincenzi

Division of Human Nutrition and Health, Istituto Superiore di Sanità, Rome, Italy

Correspondence to: Dr M Silano, Division of Human Nutrition and Health, Istituto Superiore di Sanita', Viale Regina Elena, 299, 00161 Roma, Italy; marco.silano@iss.it

Competing Interests: None declared.

\section{Reference}

1 Walker-Smith J, Guandalini S, Schmitz J, et al. Revised criteria for diagnosis of coeliac disease. Report of Working Group of European Society of Paediatric Gastroenterology and Nutrition.

J Pediatr Gastroenterol Nutr 1990;65:909-11.

\section{Hypergastrinaemia in patients infected with Helicobacter pylori treated with proton pump inhibitors}

We read with interest the commentary by McColl on Helicobacter pylori infection and long term proton pump inhibitor (PPI) therapy (Gut 2004;53:5-7).

It is remarkable that he did not mention gastrin although hypergastrinaemia is a result of reduced gastric acidity ${ }^{1}$ as well as Helicobacter pylori infection, ${ }^{2}$ and that patients with $H$ pylori infection treated with PPI have additive hypergastrinaemia. ${ }^{3}$ Hypergastrinaemia predisposes to gastric carcinoids in animals $^{45}$ and humans ${ }^{67}$ as well as to malignant ECL cell derived tumours (gastric carcinomas) in animals ${ }^{8}$ and humans. ${ }^{9} 10$

Interestingly, the carcinogenic effect of $H$ pylori infection may be completely explained by its hypergastrinaemic effect, ${ }^{11}$ a work where McColl was one of the authors. Furthermore, the increased gastric cancer frequency in moderate hypergastrinaemic INS-GAS mice concomitantly infected by $H$ pylori infection ${ }^{12}$ may also be caused by increased hypergastrinaemia in infected mice. $^{13}$

To conclude, it is odd that gastrin was not taken into consideration when discussing the risk of gastric cancer following treatment with PPI in patients infected with $H$ pylori. Animal as well as human studies linking gastrin to gastric cancer give support for a strategy where $H$ pylori is eradicated in patients on long term PPI treatment.

\section{H L Waldum}

Correspondence to: Professor H L Waldum, Norwegian University of Science and Technology, Department of Clinical and Molecular Medicine, Trondheim University, Trondheim N-7006, Norway; helge.waldum@medisin.ntnu.no

Competing Interests: None declared.

\section{References}

1 Korman MG, Strickland RG, Hansky J. Serum gastrin in chronic gastritis. BMJ 1971;2:16-18.

2 Moss SF, Calam J. Acid secretion and sensitivity to gastrin in patients with duodenal lulcer: effect of eradication of Helicobacter pylori. Gut 1993;34:888-92
3 Schenk BE, Kuipers EJ, Klinkenberg-Knol EC, et al. Hypergastrinaemia during long-term omeprazole therapy: influences of vagal nerve function, gastric emptying and Helicobacter pylori infection. Aliment Pharmacol Ther

1998; 12:605-12.

4 Havu N. Enterochromaffin-like cell carcinoids of gastric mucosa in rats after life-long inhibition of gastric acid secretion. Digestion

1986;35(suppl):42-55.

5 Hirayama F, Takagi S, Iwao E, et al. Development of poorly differentiated adenocarcinoma and carcinoid due to long-term Helicobacter pylori colonization in Mongolian gerbils. J Gastroenterol 1999;24:450-4.

6 Sjöblom S-M, Sipponen P, Karonen S-L, et al. Argyrophil cell hyperplasia and carcinoid tumours in oxyntic mucosa of the stomach. Dependence on duration of pernicious anaemia. Eur J Gastroenterol Hepatol 1991;31:153-7.

7 Cadiot G, Vissuzaine C, Potet F, et al. Fundic argyrophic carcinoid tumor in a patient with sporadic-type Zollinger-Ellison syndrome. Dig Dis Sci 1995;40:1275-8.

8 Waldum HL, Rørvik H, Falkmer S, et al. Neuroendocrine (ECL-cell) differentiation of spontaneous gastric carcinomas of cotton rats (Sigmodon hispidus). Lab Anim Sci 1999;49:241-7.

9 Qvigstad G, Qvigstad T, Westre B, et al. Neuroendocrine differentiation in gastric adenocarcinomas associated with severe hypergastrinemia and/or pernicious anemia. APMIS 2002;110:132-9.

10 Qvigstad G, Falkmer S, Westre B, et al. Clinical and histopathological tumour progression in $\mathrm{ECL}$ cell carcinoids ("ECLomas"). APMIS 1999;107:1085-93.

11 Hansen S, Vollset SE, Ardill JES, et al. Hypergastrinemia is a strong predictor of distal gastric adenocarcinoma among Helicobacter pylori infected persons. Gastroenterology 1997; 1 12:A575.

12 Wang TC, Dangler CA, Chen D, et al. Synergistic interaction between hypergastrinemia and Helicobacter infection in a mouse model of gastrin carcinoma. Gastroenterology 2000; 1 18:36-47.

13 Waldum HL, Brenna E, Martinsen TC. Safety of proton pump inhibitors. Aliment Pharmacol Ther 2000; 14:1537-8.

\section{Terminal ileal biopsies should not} be used to document extent of colonoscopic examination

We commend the British Society of Gastroenterology and the authors for the excellent publication of guidelines for the management of inflammatory bowel disease in adults (Gut 2004;53(suppl V):vi-16). However, we feel that their recommendation for routine terminal ileal biopsying is inappropriate. Although it is important to biopsy the terminal ileum if there is macroscopic evidence of an abnormality, their statement that "a terminal ileal biopsy performed at colonoscopy documents the extent of examination" is not recommended practice, due to the potential risk of variant Creutzfeld-Jacob disease transmission from prion proteins which are prevalent in the lymphoid tissue of Peyer's patches in the ileum. Although the use of disposable forceps may reduce the risk of transmission, there could still be contamination of the intubation channel of the colonoscope and prion protein is resistant to the standard endoscopic cleaning process. ${ }^{1}$ If the extent of examination needs to be documented, then a photograph of the ileocaecal valve or ileal mucosa is preferable.

It is worth emphasising that prion protein may be present in any part of the gastrointestinal tract $^{2}$ and random biopsy of gastrointestinal mucosa for reasons other than confirming an endoscopic abnormality or excluding microscopic colitis is not accepta- ble. Similarly, for surveillance colonoscopy where multiple biopsy is recommended, the risk benefit ratio of this policy must be supported by the clinical indications.

M D Rutter

University Hospital of North Tees, Stockton-on-Tees, Cleveland, UK

M G Bramble

James Cook University Hospital, Middlesbrough, Cleveland, UK

Correspondence to: Dr M D Rutter, University Hospital of North Tees, Stockton-on-Tees, Cleveland, TS19 8PE, UK; matt.rutter@nth.nhs.uk

Competing Interests: None declared.

\section{References}

1 Bramble MG, Ironside JW. Creutzfeld-Jakob disease: implications for gastroenterology. Gut 2002;50:888-90.

2 Herzog C, Sales N, Etchegaray N, et al. Tissue distribution of bovine spongiform encephalopathy agent in primates after intravenous or oral infection. Lancet 2004;363:422-8.

\section{$\lg G$ food antibodies should be studied in similarly treated groups}

The recent paper by Atkinson and colleagues (Gut 2004;53:1459-1464) regarding IgG food antibodies and irritable bowel syndrome (IBS) fails to compare like with like. Regardless of the IgG results, the treatment group excluded significantly different foods to the control group, particularly those foods which appear to exacerbate symptoms of IBS. Of particular concern is the "yeast exclusion" diet. A low yeast diet is not a recognised diet in standard textbooks of dietetics and nutrition. However, alternative practitioners offering such a "yeast exclusion diet" sometimes recommend exclusion of a wide range of foods, such as: bakery products, alcoholic beverages, many other beverages including commercial fruit juices, cereals, condiments, dairy produce, fungi, meat products (hamburgers, sausages, and cooked meats made with bread or breadcrumbs), yeast extracts (Bisto, Marmite, Oxo, Bovril, Vegemite, gravy browning, and all similar extracts), all B vitamin preparations, and sometimes, most worryingly, "sugar foods" (sugar, sucrose, fructose, maltose, lactose, glycogen, glucose milk, sweets, chocolate, sweet biscuits, cakes, candies, cookies, puddings, desserts, canned food, packaged food, hamburgers, honey, mannitol, sorbitol, galactose, monosaccharides, polysaccharides, date sugar, turbinado sugar, molasses, maple syrup, most bottled juices, all soft drinks, tonic water, milkshakes, raisins, dried apricots, dates, prunes, dried figs, and other dried fruit).

Therefore, regardless of IgG antibody status, the dietary restrictions in one group are not controlled for by the other group, and hence the conclusion may not be valid.

It would also be helpful to know if any of the patients with IgG antibodies to a particular antigen also had IgE antibodies to the same antigen.

W A C Sewell

Correspondence to: Dr W A C Sewell, Path Links Immunology, Scunthorpe General Hospital, Scunthorpe DN15 7BH, UK; carrock.sewell@nlg.nhs.uk

Competing Interests: None declared. 


\section{IgG antibodies to foods in IBS}

We read with interest the article by Atkinson et al (Gut 2004;53:1459-64). The authors describe an important advance in our understanding of the putative role of inflammation in irritable bowel syndrome (IBS). However, we wonder whether their conclusion that assay of IgG antibodies may have a role in identifying candidate foods for elimination to treat patients with IBS may be a step too far. The four foods to which the patients most commonly formed antibodies and hence the four foods most commonly eliminated from the "true diet" were yeast $(86.7 \%)$, milk $(84.3 \%)$, whole egg $(58.3 \%)$, and wheat (49.3\%). The "sham diet" involved eliminating foods to which the patients had not formed antibodies and, therefore, in the sham group the exclusion rates for yeast, milk, whole egg, and wheat were very low $(0 \%, 1.3 \%, 26.7 \%$, and $8 \%$ respectively). It is therefore difficult to assess whether a diet excluding these foods would have led to symptomatic improvement in all patients, regardless of their antibody status.

Furthermore, the foods to which the study group commonly formed antibodies were similar to those already identified as leading to symptomatic benefit in patients with IBS when excluded from their diet. In a review cited by Atkinson and colleagues, ${ }^{1}$ it was noted that in eight trials of exclusion diets in IBS, seven identified dairy products and five identified wheat as worsening symptoms. It is not clear whether the difference in improvement in symptoms seen in the current study between true and sham groups can be explained simply by the omission of these foods. This could in practice eliminate the need for antibody testing.

J E D Mawdsley, P Irving, R Makins Barts and the London School of Medicine and Dentistry, London, UK

Correspondence to: Dr J E D Mawdsley, St Bartholomew's and Royal London Hospital, Turner St, London El 2AD, UK; joelmawdsley@yahoo.com

Competing Interests: None declared.

\section{Reference}

1 Burden S. Dietary treatment of irritable bowel syndrome: current evidence and guidelines for future practice. J Hum Nutr Diet 2001; 14:231-41.

\section{Influence of dietary factors on the clinical course of inflammatory bowel disease}

Jowett et al reported in their elegant study on the role of diet in maintaining remission in patients with ulcerative colitis (Gut 2004;53:1479-84). Surely the effect of diet has an essential, but often forgotten, role in altering the course of disease in all types of inflammatory bowel diseases. This role does not necessarily act by maintaining patients in remission clinically, but perhaps more importantly by minimising the activities of the disease and rendering it quiescent.

We have recently reported a case of active stricturing Crohn's disease in an adult female patient with high stoma output. ${ }^{1}$ She was treated solely with casein base formula (Modulen IBD-Nestle, Vevey, Switzerland) for three weeks. Her stoma output was reduced from $2800 \mathrm{ml}$ to $400 \mathrm{ml}$ per day by day 10. Serum albumin and serum protein significantly increased also. She subjectively felt better and pain free and stopped her opiate and non- opiate formula. The casein based formula is a nutritionally complete formulation containing a natural antiinflammatory growth factor, transforming growth factor $\alpha 2$. The mechanism for inducing remission in our patient was possibly inhibition of expression of MHC class II protein in downregulating the inflammatory response. ${ }^{2}$

Previous studies have shown that there is a decrease in plasma antioxidant defences in all types of inflammatory bowel disease. ${ }^{3}$ This is mirrored by an increase in free radical peripheral leucocyte DNA damage. It is therefore possible that the casein based formula acts as an antioxidant to minimise the oxidative stress that occurs in patients with active Crohn's disease. Another possible mechanism is that this formula may have a role as a prebiotic by stimulating the activity of bacteria which are already present in the gut.

Remission induced in our case study highlights the part played by a casein based formula in the management of adult Crohn's disease. The encouraging result demonstrates the need to treat similar cases with dietary measures first. This opportunity should not be missed as it may well obviate the need for surgical intervention or administration of potent pharmacotherapeutic agents which carries the risk of several comorbidities.

N Y Haboubi, $S$ Jones

Nevill Hall Hospital, Gwent, South Wales, UK

Correspondence to: $\operatorname{Dr} N$ Y Haboubi, Nevill Hall Hospital, Brecon Rd, Abergavenny, Gwent NP7 7EG, South Wales, UK; nadim.haboubi@ gwent.wales.nhs.uk

Competing Interests: None declared.

\section{References}

1 Jones S, Shannon H, Srivastava E, et al. A novel approach to a patient with Crohn's disease and a high stoma output: a missed opportunity? Scand J Gastroenterol 2004;4:398-400.

2 Donnet-Hughes A, Duc N, Serrant P, et al. Bioactive molecules in milk and their role in health and disease: the role of transforming growth factor- $\alpha$. Immunol Cell Biol 2000:34:49-53.

3 D'Odorico A, BortolanS, Gaardin R, et al. Reduced plasma antioxidant concentrations and increased oxidative DNA damage in inflammatory bowel disease.

Scand J Gastroenterol 2001;36:1289-94.

\section{Identification of ferroportin disease in the Indian subcontinent}

Haemochromatosis is a common inherited disorder of iron metabolism, characterised by excessive iron absorption and deposition in tissues. The majority of cases are associated with mutations in the HFE gene and inherited in an autosomal recessive manner.' Autosomal dominant forms of haemochromatosis have been reported, mainly associated with mutations in the ferroportin 1 gene. ${ }^{2}$ This syndrome, termed type 4 haemochromatosis or more recently ferroportin disease, ${ }^{3}$ is usually characterised by an early increase in serum ferritin with normal transferrin saturation. Iron accumulation is most prominent in Kupffer cells and other macrophages, in addition to hepatocytes. Some patients do not tolerate venesection therapy well and can develop anaemia. Hereditary iron overload disorders appear to be uncommon in Asia. Secondary iron overload due to beta thalassaemia is relatively common in the Indian subcontinent. However, primary iron overload disorders and HFE mutations appear to be rare and cases have not been well characterised in this region. ${ }^{45}$ We identified a patient from the Indian subcontinent with features typical of ferroportin disease.

A 36 year old female of Sri Lankan origin presented for a routine medical examination in December 2003. She was found to have an elevated serum ferritin of $3145 \mu \mathrm{g} / \mathrm{l}$. Her serum iron $(17.1 \mu \mathrm{mol} / \mathrm{l})$ and transferrin saturation $(29 \%)$ were normal. Liver functions tests, blood glucose, and thyroid studies were all normal. Physical examination was normal and she had no significant past medical history or risk factors for iron overload.

C282Y, H63D, and S65C HFE gene mutations were all negative and she had no family history of iron overload. Her mother and three siblings all had normal serum ferritin levels. Her father died of ischaemic heart disease aged 48 years.

A magnetic resonance imaging scan showed hepatic iron overload. Liver biopsy showed grade 3-4 iron deposition within hepatocytes and Kupffer cells; no fibrosis or cirrhosis was evident (fig 1). The hepatic iron concentration was $17700 \mu \mathrm{g} / \mathrm{g}$ dry weight and hepatic iron index was 9.1.

Venesection therapy was initially poorly tolerated with the development of anaemia following the first two $500 \mathrm{ml}$ venesections. Her haemoglobin is now stable on a programme of $300-500 \mathrm{ml}$ venesections every three weeks.

The features of ferroportin disease in this patient led us to sequence the ferroportin 1 gene, as previously described. ${ }^{6}$ Analysis of the DNA sequence revealed a heterozygous three base pair deletion (TTG) in exon 5. This is the same deletion, Vl62del, described by us and others in haemochromatosis patients from Australia, the UK, Italy, and Greece..$^{6-9}$

This is the first report to identify Vl62del or indeed any ferroportin 1 mutation in an individual from the Indian subcontinent. Identification of V162del in an Asian patient confirms that this mutation is likely to be the most common mutation of ferroportin 1 and the most common cause of non-HFE associated haemochromatosis. The wide geographical distribution of this mutation suggests that it is a recurrent mutation that has repeatedly arisen in distinct populations, probably by slippage mispairing.

Iron overload in this patient was typical of ferroportin disease. At the time of diagnosis she was asymptomatic and had no fibrosis on liver biopsy. Whether fibrosis or clinical complications will develop with age if iron stores are not depleted is unclear.

In conclusion, we have identified the V162del mutation of ferroportin 1 in a fifth geographical location, emphasising that this mutation is the most common and widely distributed mutation which causes non-HFE haemochromatosis. We have identified V162del in a region where iron overload disorders have not been well characterised. Analysis of this and other ferroportin 1 mutations may be useful in the study of iron overload disorders in this region and may be the basis of hitherto unexplained cases of iron overload. 

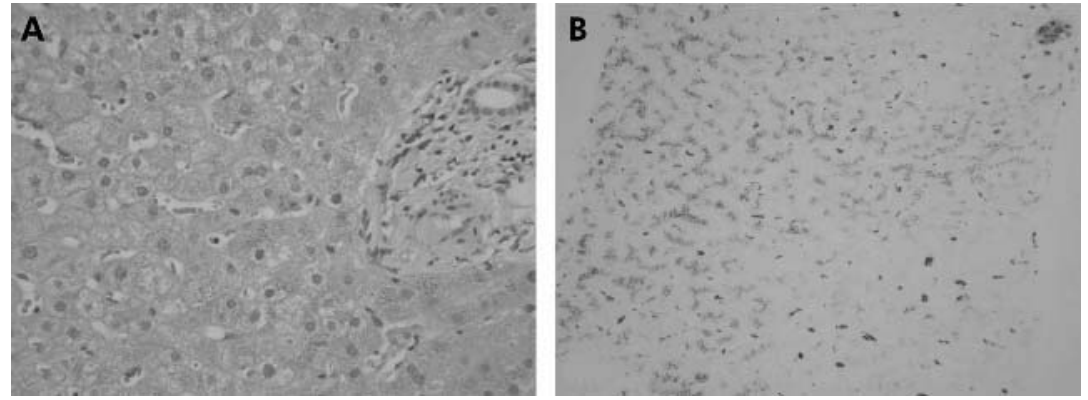

Figure 1 Liver biopsy sections from our patient stained with (A) haematoxylin and eosin and (B) Perls' Prussian blue (magnification 100×). Grade 3-4 iron is prominent in hepatocytes and Kupffer cells.

\section{Acknowledgements}

This work was supported in part by grants from the National Health and Medical Research Council of Australia (953219), the National Institutes of Health, USA (5R01DK057648-02), and the Haemochromatosis Society of Australia to VNS.

D F Wallace

Membrane Transport Laboratory, The Queensland Institute of Medical Research, Brisbane, Queensland, Australia

P Browett

Department of Molecular Medicine and Pathology, University of Auckland, and LabPlus, Auckland City Hospital, Auckland, New Zealand

P Wong

Department of Gastroenterology, Auckland City Hospital, Auckland, New Zealand

H Kua

Diagnostic Medlab, Auckland, New Zealand

R Ameratunga

LabPlus, Auckland City Hospital, Auckland, New Zealand

V N Subramaniam Membrane Transport Laboratory, the Queensland Institute of Medical Research, Brisbane, Queensland,

Australia

Correspondence to: Dr V N Subramaniam, Membrane Transport Laboratory, The Queensland Institute of Medical Research, 300 Herston Rd Herston, Brisbane, QLD 4006, Australia; nathanS@ qimr.edu.au

doi: 10.1136/gut.2004.060988

Competing Interests: None declared.

\section{References}

1 Feder JN, Gnirke A, Thomas W, et al. A novel MHC class I-like gene is mutated in patients with hereditary haemochromatosis. Nat Genet 1996:13:399-408.

2 Pietrangelo A. Non-HFE hemochromatosis. Hepatology 2004;39:21-9.

3 Pietrangelo A. The ferroportin disease. Blood Cells Mol Dis 2004;32:131-8.

4 Kaur G, Rapthap CC, Xavier M, et al. Distribution of C282Y and H63D mutations in the HFE gene in healthy Asian Indians and patients with thalassaemia major. Natl Med J India 2003:16:309-10.

5 Thakur V, Guptan RC, Hashmi AZ, et al. Absence of hemochromatosis associated Cys282Tyr HFE chronic liver disease patients in India. J Gastroenterol Hepatol 2004; 19:86-90.

6 Wallace DF, Pedersen P, Dixon JL, et al. Novel mutation in ferroportin 1 is associated with autosomal dominant hemochromatosis. Blood 2002; 100:692-4

7 Devalia V, Carter K, Walker AP, et al. Autosomal dominant reticuloendothelial iron overload associated with a 3-base pair deletion in the ferroportin 1 gene (SLC11A3). Blood 2002; 100:695-7.

8 Roetto A, Merryweather-Clarke AT, Daraio F, et al. A valine deletion of ferroportin 1: a common mutation in hemochromastosis type 4 . Blood 2002;100:733-4.

9 Cazzola M, Cremonesi L, Papaioannou M, et al. Genetic hyperferritinaemia and reticuloendothelial iron overload associated with a three base pair deletion in the coding region of the ferroportin gene (SLC 1 1A3). Br J Haematol 2002;119:539-46.

\section{BOOK REVIEW}

\section{Morson and Dawson's Gastrointestinal Pathology, 4th edn}

Edited by D W Day, J R Jass, A B Price, et al. $£ 175.00$, pp 692. ISBN 0-632-04204-4

Why do people buy s book such as this, which involves a not inconsiderable financial outlay (even if you box clever and make it tax firstly, for use as a bench book, and secondly, for information on the pathological basis of gastrointestinal disease for interest, teaching, or indeed research purposes.

On the first criterion, this book succeeds, usually quite brilliantly. As a vade mecum on gastrointestinal pathology it should be on the shelf of every pathologist who engages in the reporting of such material. In my view, the book is more user friendly than the gene mutation and low frequency of hemochromatosis phenotype in nonalcoholic Massachusetts: Blackwell Publishing, 2003, deductible)? I think for two main reasons-
competition-Fenoglio-Preiser and Goldman to name but two-and is certainly more readable. I would therefore extol its virtues unreservedly in this respect.

On the second criterion, as a source book, I suppose the correct word is patchy. Some sections, for example that on colorectal tumours, is admirable in this respect, whereas other sections are more limited in scope and even cursory in their treatment of the pathobiology. There is also the problem of the unavoidable intrinsic delay in producing such a book, resulting in reference lists which are some years away from the publication date. I am aware however that my personal outlook is not that of most individuals who will purchase this volume so I am probably being over critical. It is, after all, quintessentially a bench book, and excellent at that.

However, I do have one real beef. In any multiauthor work there is bound to be variation, but here we are not told which one of the stellar caste were responsible for which section or chapter. Of course we can make informed guesses about the Barrett's or colorectal carcinoma sections, but who did the GIST bit? Because of some (minor) errors in the criteria for the diagnosis of malignancy, I have tried to berate a number of authors who have all denied responsibility, and blamed someone else-usually the author(s) absent at the time. Not good enough.

I have to concede however that the authors have succeeded in producing perhaps the text in gastrointestinal pathology, which is a credit to both themselves and the discipline in the UK. I congratulate them.

N A Wright

\section{CORRECTIONS}

doi: 10.1136/gut.2003.025494corr 1

In the January 2005 issue of Gut, one of the author's names of the paper entitled Human peripheral and gastric lymphocyte responses to Helicobacter pylori NapA and AphC differ in infected and uninfected individuals $(\mathrm{H} \mathrm{J}$ Windle, Y S Ang, V A Morales, R McManus, and D Kelleher. Gut 2005;54:25-32) was cited incorrectly. V A Morales should read V AthieMorales. The journal apologises for this mistake.

\section{doi: 10.1136/gut.2003.026807corr 1}

In the December issue of Gut fig 1 in the paper by AJG Bell et al (Human lymphocyte stimulation with pouchitis flora is greater than with flora from a healthy pouch but is suppressed by metronidazole. Gut 2004;53: 1801-1805) is incorrect. The labels for fig $1 \mathrm{C}$ are inverted; the squares should have been labelled HetNon and the triangles HetPM. The legend is also incorrect because the label for flora grown on agar without metronidazole is HetNon, not HetP as stated. 